\title{
Ectopic Thyroid Tissue in the Adrenal Gland
}

\author{
Jolanta Gourmaud • Massimo Bongiovanni • \\ Frederic Triponez • Marc Pusztaszeri
}

Published online: 27 June 2013

(C) Springer Science+Business Media New York 2013

\section{Case History}

A 51-year-old female presented with a left adrenal mass. The lesion was an incidental finding on an abdominal CT scan performed for chronic megacolon. The mass was discovered in 1996 and slowly enlarged in size during the follow-up ( $2.5 \mathrm{~cm}$ in 1996, $4.2 \mathrm{~cm}$ in 2009). Radiologically, the mass had tissular density with apical hypodensity and some calcifications. The endocrine work-up did not show abnormal adrenal hormone levels. Left endoscopic adrenalectomy was performed.

\section{What is Your Diagnosis?}

Pathological Diagnosis: Ectopic Thyroid Tissue in the Adrenal Gland with a Cystic Component and Focal Nuclear Atypia

Grossly, the lesion measured $3.3 \mathrm{~cm}$ in the greatest diameter. It was cystic and multilocular (Fig.1a), filled with yellow jelly content. Microscopically, there were cystic spaces lined by epithelial cells and septa containing rare follicular structures intermingled with the adrenal cortex. Some dystrophic calcifications, cholesterol crystals, and macrophages were present. The epithelial lining was flat or cuboidal with polymorphic and sometimes overlapping nuclei. The cystic walls were generally thin, composed of fibrous tissue, but sometimes thicker with

J. Gourmaud • M. Pusztaszeri $(\square)$

Department of Clinical Pathology, Geneva University

Hospital, 1 rue Michel-Servet, 1211 Genève 14, Switzerland

e-mail: marc.pusztaszeri@hcuge.ch

M. Bongiovanni

Institute of Pathology, Locarno, Switzerland

F. Triponez

Department of Thoracic and Endocrine Surgery,

Geneva University Hospital, Geneva, Switzerland some smooth muscle cells. Foci of the adrenal cortex and follicular structures were found admixed within the fibrous tissue. Those follicles consisted of flat cells centered by eosinophilic amorphous material (colloid-like), consistent with thyroid follicles. Some nuclear features suspicious for papillary thyroid carcinoma (enlarged and overlapping nuclei, clear chromatin, some nuclear grooves, and rare nuclear pseudoinclusions) were observed in some follicles (Fig. 1b-d) and in some of the cystlining cells. No psammoma bodies were found.

Immunohistochemistry was performed. The cyst-lining cells and the follicular cells were positive for keratin, thyroglobulin, and thyroid transcription factor-1 (TTF-1) (Fig. 1e). Galectin-3 and HBME-1 were focally positive in the cystlining cells, but were negative in the follicles (Fig. 1f).

\section{Comment}

The most important differential diagnosis to consider in this case was a cystic metastasis from a papillary thyroid carcinoma (PTC), especially in the presence of some nuclear atypia and partial expression of Galectin-3 and HBME-1, which are considered as general markers of thyroid malignancy [1]. For that reason, an additional clinical work-up was performed. There were no other lesions on multiple abdominal CT scans. Thyroid ultrasonography showed a few nodules with benign characteristics, and an I-123 whole body scan coupled with thoracic and abdominal CT scan showed only physiological uptake in the thyroid. There was no clinical evidence of thyroid malignancy 2 years after the adrenalectomy. Moreover, the adrenal lesion was also known to be present for at least 14 years. This would be very unusual for a metastatic PTC, although extremely slowly growing metastases from PTC have been reported, with intervals between detection of the primary tumor and metastases as long as 45 years [2]. Thereby, we assumed that a metastasis from a PTC or from a struma ovarii could be 
Fig. 1 a Macroscopically, the adrenal gland is centered by a multilocular cystic lesion with jelly content (blue square $=1 \mathrm{~cm}^{2}$ ). b Histologically, the cystic lining is flat to cuboidal, and the septa are fibrous containing thyroid follicles and adrenal cortical cells with clear cytoplasm (original magnification $\times 200$ ). $\mathbf{c}$ Higher magnification of follicles intermingled with the adrenal cortex (original magnification $\times 400$ ). d Some follicles show nuclear atypia suspicious for papillary thyroid carcinoma: enlarged nuclei, clear chromatin, and nuclear grooves (original magnification $\times 400$ ). $\mathrm{e}$ TTF-1 immunostain showing nuclear positivity in follicles and cystic lining cells (original magnification ×400). $f$ HBME-1 immunostain is positive in the cystic epithelium but negative in the follicles (original magnification $\times 400$ )
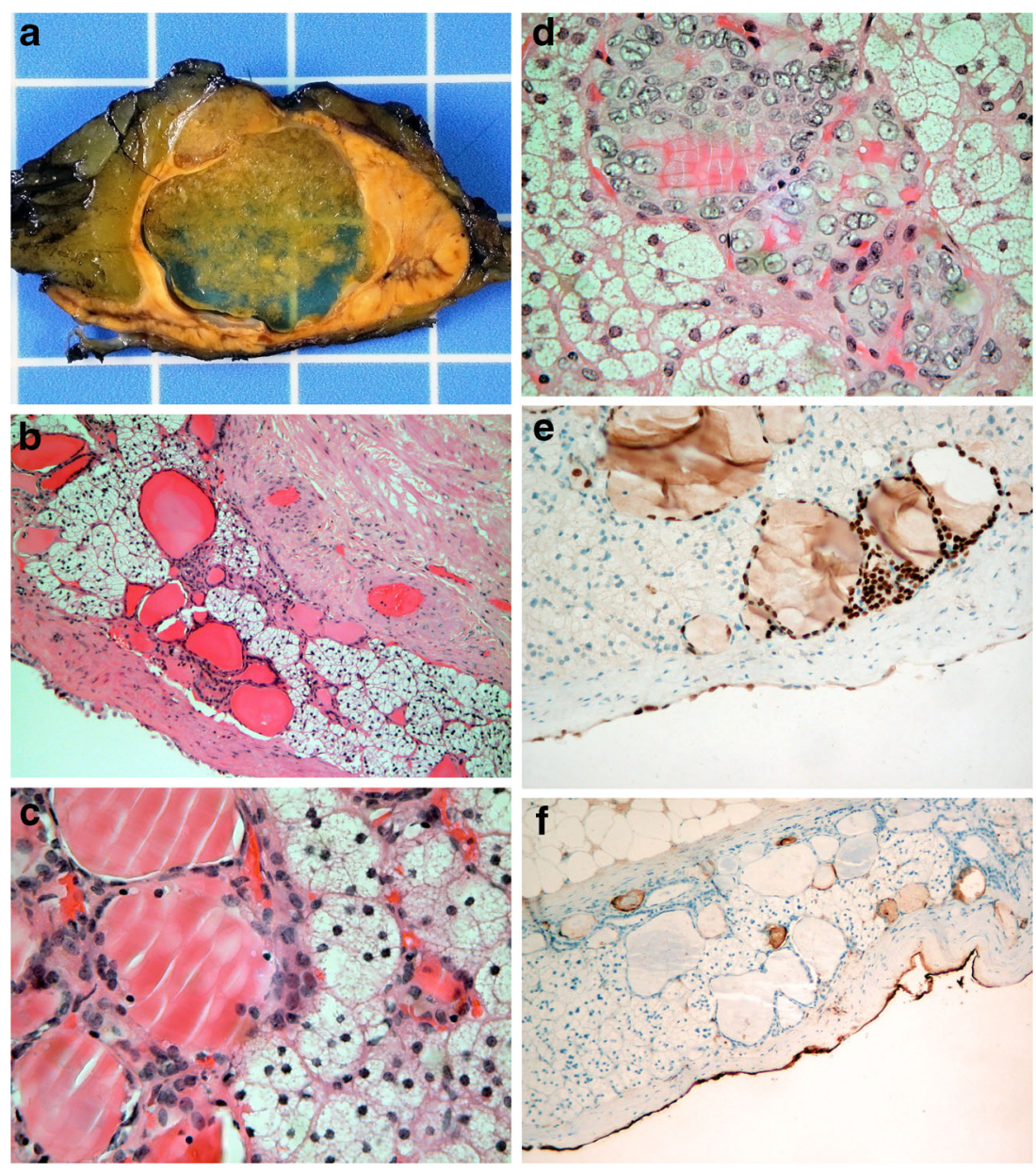

reasonably excluded, and we concluded that the adrenal mass was consistent with ectopic thyroid tissue with atypia. Although the nuclear atypia was most likely reactive in nature, we also assumed that a papillary carcinoma arising from ectopic thyroid tissue in the adrenal could not be completely ruled out.

Ectopic thyroid tissue in the adrenal gland is an extremely rare finding. To the best of our knowledge, only nine cases have been reported in the English literature [3-9], mainly by Japanese authors [3-7]. Patients were almost exclusively women (male/female, 1/8), and their age ranged from 38 to 67 years. Most of the lesions were cystic (eight out of nine) and incidentally discovered on imaging. Their size ranged from 0.8 to $5 \mathrm{~cm}$. Two lesions were associated with secreting adrenal adenoma [7, 8]. In one case, ectopic thyroid was associated with a papillary microcarcinoma of the thyroid [8].

Etiology of ectopic thyroid tissue in the adrenal gland is unknown and is difficult to explain based on the embryological development of the thyroid gland. The thyroid develops from the endoderm and descends from the base of the tongue to the anterior trachea. Therefore, ectopic thyroid tissue is common in the cervical and mediastinal region [9]. It is also possible to find ectopic thyroid tissue below the diaphragm in several organs of endodermic origin, including the gallbladder [10], ovary [11], small intestine, mesentery [12], pancreas [13], duodenum [14], and vagina [15]. On the other hand, the adrenal gland is composed of a medulla which is ectodermic in origin, and the cortex is developed from the mesoderm. Other possible explanations for this pathology would be metaplasia, teratoma, or tumor originating from adrenal stem cells, akin to adrenal myelolipoma [16].

The most important issue in assessing a case of thyroid tissue in an ectopic location is the exclusion of a metastasis from a thyroid carcinoma. The presence of atypical follicular cells should also raise the possibility of a papillary carcinoma arising in ectopic thyroid tissue. Indeed, an ectopic thyroid tissue can be subject to the same pathological processes as normal eutopic thyroid tissue such as inflammation, hyperplasia, and tumorigenesis [17]. A careful history and histological examination is necessary. Clinically, thyroid lesions and other metastases have to be excluded. Thyroglobulin and TTF-1 immunostaining confirm the thyroid differentiation, while Galectin-3 and HBME-1, although not specific, may support malignancy. Testing for BRAF V600E mutation may also be helpful in the differential diagnosis $[9,18]$. However, although the mutation is highly specific for PTC, its absence does not rule out malignancy because of low sensitivity, especially in some variants of PTC such as the follicular variant. The mutation can also be screened for by immunohistochemistry, 
with a very high accuracy [19]. Other potential sources of thyroid tissue in an ectopic location include a metastasis from a struma ovarii in females and a metastasis from the recently described and uncommon thyroid-like follicular carcinoma of the kidney. However, the latter is typically negative for TTF-1, HBME-1, and Galectin-3 [20].

\section{References}

1. Prasad ML, Pellegata NS, Huang Y, Nagaraja HN, de la Chapelle A, Kloos RT. Galectin-3, fibronectin-1, CITED-1, HBME1 and cytokeratin-19 immunohistochemistry is useful for the differential diagnosis of thyroid tumors. Mod Pathol 18:48-57, 2005

2. Kikuchi R, Isowa N, Tokuyasu H, Fukuda K, Kawasaki Y. Lung metastases from thyroid cancer found 45 years after a right hemithyroidectomy. Chirurgia 19:439-441, 2006.

3. Tsujimura A, Takaha M, Takayama H, Sugao H, Takeda M, Kurata A. Ectopic thyroid tissue in a cystic adrenal mass. Br J Urol 77:605-606, 1996.

4. Shiraishi T, Imai H, Fukutome K, Watanabe M, Yatani R. Ectopic thyroid in the adrenal gland. Hum Pathol 30:105-108, 1999.

5. Shuno Y, Kobayashi T, Morita K, Shimizu S, Nishio Y, Ito A, Kobayashi K, Kawahara M, Teruya M. Ectopic thyroid in the adrenal gland presenting as cystic lesion. Surgery 139:580-582, 2006.

6. Takao H, Doi I, Watanabe T. Ectopic thyroid in the adrenal gland: computed tomography findings. J Comput Assist Tomogr 30:221222, 2006.

7. Hagiuda J, Kuroda I, Tsukamoto T, Ueno M, Yokota C, Hirose T, Deguchi N. Ectopic thyroid in an adrenal mass: a case report. BMC Urol 6:18, 2006.

8. Bohinc BN, Parker JC, Hope WW, Kotwall C, Turner J, Cheng W, Lloyd RV. Micropapillary thyroid carcinoma and concomitant ectopic thyroid tissue in the adrenal gland: metastasis or metaplasia? Thyroid 21:1033-1038, 2011.

9. Romero-Rojas A, Bella-Cueto MR, Meza-Cabrera IA, CabezueloHernández A, García-Rojo D, Vargas-Uricoechea H, Cameselle-
Teijeiro J. Ectopic Thyroid Tissue in the Adrenal Gland: Report of 2 Cases with Pathogenetic Implications. Thyroid 2013. doi:10.1089/ thy.2013.0063.

10. Cassol CA, Noria D, Asa SL. Ectopic thyroid tissue within the gall bladder: case report and brief review of the literature. Endocr Pathol 21:263-265, 2010.

11. Macleod DH. Struma Ovarii (Thyro-Dermoid). A note on the teratomatous origin. Proc R Soc Med 25:1386-1391, 1932.

12. Gungor B, Kebat T, Ozaslan C, Akilli S. Intra-abdominal ectopic thyroid presenting with hyperthyroidism: report of a case. Surg Today 32:148-150, 2002.

13. Eyuboqlu E, Kapan M, Ipek T, Ersan Y, Oz F. Ectopic thyroid in the abdomen: report of a case. Surg Today 29:472-474, 1999.

14. Takahashi T, Ishikura H, Kato H, Tanabe T, Yoshiki T. Ectopic thyroid follicles in the submucosa of the duodenum. Virchows Arch A Pathol Anat Histopathol 418:547-550, 1991.

15. Kurman RJ, Prabha AC. Thyroid and parathyroid glands in the vaginal wall: report of a case. Am J Clin Pathol 59:503-507, 1973.

16. Bishop E, Eble JN, Cheng L, Wang M, Chase DR, Orazi A, O'Malley DP. Adrenal myelolipomas show nonrandom X-chromosome inactivation in hematopoietic elements and fat: support for a clonal origin of myelolipomas. Am J Surg Pathol 30:838-843, 2006.

17. Klubo-Gwiezdzinska J, Manes RP, Chia SH, Burman KD, Stathatos NA, Deeb ZE, Wartofsky L. Clinical review: Ectopic cervical thyroid carcinoma-review of the literature with illustrative case series. J Clin Endocrinol Metab 96:2684-2691, 2011.

18. Rossi ED, Martini M, Straccia P, Larocca LM, Fadda G. Detection of ectopic thyroid remnants: a serious diagnostic dilemma. When molecular biology and immunohistochemistry can solve the problem. Pathol Res Pract 209:59-61, 2013.

19. Capper D, Preusser M, Habel A, Sahm F, Ackermann U, Schindler G, Pusch S, Mechtersheimer G, Zentgraf H, von Deimling A. Assessment of BRAF V600E mutation status by immunohistochemistry with a mutation-specific monoclonal antibody. Acta Neuropathol 122:11-19, 2011.

20. Alessandrini L, Fassan M, Gardiman MP, Guttilla A, Zattoni F, Galletti TP, Zattoni F. Thyroid-like follicular carcinoma of the kidney: report of two cases with detailed immunohistochemical profile and literature review. Virchows Arch 461:345-350, 2012. 